\title{
Knowing What Matters: An Expanded Study of School Bond Elections in Michigan, 1998-2006 ${ }^{1}$ \\ Alex J. Bowers ${ }^{2,3}$, Scott Metzger ${ }^{4}$, Matthew Militello ${ }^{5}$
}

\begin{abstract}
This study investigates what factors are associated with the likelihood of passing school facility construction bonds by local district election. It uses statewide data from Michigan, 19982006, to examine the outcome of 789 bond elections in terms of ten variables: amount of the bond request; district enrollment; district locale; percentage of students receiving free school lunches; percentage of the district population with only a high school degree; the district's long-term debt; voter turnout; the day of the calendar year on which the election is held; the number of the bond proposal on the ballot; and the inclusion of technology in the ballot proposal's wording. The logistic regression analysis finds that bond amount, percentage of students receiving free lunches, percentage of district population with only a high school degree, voter turnout, and being further down on the ballot are all negative and significant factors. District long-term debt and holding the election later in the calendar year are both positive and significant factors. District enrollment numbers are nonsignificant. In terms of district locale (using mid-sized city/suburban districts as the reference group), being a small town and rural district is a negative and significant factor.
\end{abstract}

Keywords: Bond issues, school finance, logistic regression, elections, voters

\section{INTRODUCTION}

Every year school districts across the U.S. bring before their local voters requests for money to build new or upgrade existing school facilities. Funds to pay for capital-improvement projects are usually raised through school bonds-borrowing money that is paid back at interest over time with increased local property taxes approved by voters. In this longstanding system for building and maintaining educational capital infrastructure, today's new school building projects become tomorrow's long-term debt. Districts that cannot secure funding from their voters for up-to-date capital improvements may fall behind more successful neighboring districts in providing quality teaching and learning conditions. This can be potentially damning in regions where high-stakes accountability puts school districts in a results-driven race and school-choice competition empowers families to move their students into whichever nearby district looks to be doing the best.

\footnotetext{
${ }^{1}$ This document is a pre-print of this manuscript, published in 2010 in the Journal of Education Finance. Recommended citation:

Bowers, A.J., Metzger, S.A., Militello, M. (2010) Knowing What Matters: An Expanded Study of School Bond Elections in Michigan, 1998-2006. Journal of Education Finance, 35(4), 374396. doi:10.1353/jef.0.0024

${ }^{2}$ Teachers College, Columbia University; Bowers@tc.edu; ORCID: 0000-0002-5140-6428, ResearcherID: C-1557-2013

${ }^{3}$ Formerly at The University of Texas at San Antonio at the time of publication

${ }^{4}$ The Pennsylvania State University; sam59@psu.edu

${ }^{5}$ North Carolina State University; mcmilite@ ncsu.edu

Note: This document was last updated on July 29, 2013

Bowers, Metzger \& Militello (2010) Knowing the Odds
}

Given that adequate capital facilities are a very publically visible component in this equation, school district leaders need to find strategies for convincing local voters to approve bond requests However, do different types of districts experience different chances? What really matters when it comes to getting school bond elections passed?

Despite the importance of school bond passage to U.S. school districts, the area is surprisingly under-researched by scholars. To explain what influences the likelihood of passing or failing school bond elections, this study builds on prior work (Bowers, Metzger and Militello, 2010) looking at the context of one particular state over an expanded span of time: Michigan, 1998-2006. Our purpose is to investigate variables suggested by a review of the limited prior research available to test a model of the likelihood of a bond request getting passed. We examine the following ten variables: amount of the bond request; district enrollment; district locale; percentage of students receiving free school lunches; percentage of the district population with a high school degree; the district's long-term debt; voter turnout; the day of the calendar year on which the election is held; the number of the bond proposal on the ballot; and the inclusion of technology in the ballot proposal's wording.

Michigan is of wider interest because it is representative of Midwestern states that have experienced an economic downturn in the post-industrial U.S. economy over the past several decades. Looking at Michigan (which had a total of 568 public school districts in 2006) may illuminate the tensions and problems that similar states with a declining population and industrial base may also face in funding local educational infrastructure. Our study is novel because it examines all capital facilities bond elections for an entire state over nearly a full decade - an approach rarely taken in the past. Rather than depending on decades-old research, non-empirical or unpublished dissertations, a thin sliver of time, or narrow set of variables, our study aims to take into consideration past scholarship in building and testing a new model that can inform emerging theory on school facilities bond passage.

Previous Research on School Capital Expenditure Bond Requests

Historically, U.S. school districts have financed capital improvements through local bond elections (Duncombe, and Wang, 2009; Sielke, Dayton, Holmes, and Jefferson 2001). Hence, understanding why bond requests are passed or rejected is an urgent issue for school district leaders, local communities, and educational researchers. Studies of school capital expenditure outcomes have conceptual roots in theories of public choice. More prevalent are normative models that emerged from both the theories of public choice and from data on capital expenditure elections. Both public choice theory and the derived normative models help researchers to identify variables for empirical studies.

Public choice theory (Mueller, 2003) has identified multiple factors that influence voter choice, including the "rational actor" 
model, self-interest (Brodsky and Thompson 1993; Piele and Hall 1973b; Sanders 1988; Shabman and Stephenson 1994), trust in public officials (Olsen 1965), and loyalty (Berkman and Plutzer 2004). Often these factors compete with one another. For example, Berkman and Plutzer (2004) found that "loyalty-an emotional bond between residents and their community's institutions - competes with and often trumps instrumental self interest" (p. 1178). Together, from the economics research perspective, public choice theory has focused on modeling individual voter behaviors and the effects on bond elections (Balsdon, Brunner, and Rueben 2003). Another equally interesting strand of research has focused on modeling the factors associated with bond election outcome. This research can be classified into two main categories, normative and empirical models of bond passage.

Normative models have emerged as a bridge between pubic choice theory and the pragmatic need to develop specific strategies to enable districts to successfully pass school bonds for capital improvements. In reviewing available studies (Boschee 2003; Boschee and Holt 1999; Conrad 2002; Crader, Holloway, and Stauffacher 2002; Davis and Tyson 2003; Holt 2002; Johnson 2008; Lifto and Senden 2006; Nagardeolekar and Merritt 2006), a range of commonalities emerge in the prescriptive findings: clear and compelling vision and ballot language; convincing the public the cost and design are the most appropriate alternative; community education, communication, and involvement in the process; support from the board of education and other governmental agencies; get out the "yes" vote, especially among parents and senior citizens; and obtain advice from school districts that had previously won bond elections.

While procedural advice for school officials is plentiful, empirical literature on exactly what factors are associated with the likelihood of passing a bond remains sparse. Some studies focus on estimating overall expenditures. As one example from the more general municipal funding literature, Bradbury, Ladd, Perrault, Reschovsky, and Yinger (1984) examined the predictors of municipal operating expenditures, including schools, in Massachusetts in 1980 and found that significant predictors included the size of the city, the amounts of crime and poverty, overall revenue, residential income, and student enrollment in local schools. Though schools were only one type of municipal expenditure in their study, their findings highlight multiple factors that other studies specifically focused on schools and school bonds have also found are important in determining the likelihood of funding requests for school capital expenditures.

The most influential and in-depth review of factors that related to school bond passage was conducted several decades ago by Piele and Hall (1973a; 1973b). Their meta-analysis generated "partial theories" of factors that impact bond election outcomes: school district characteristics (e.g., property assessment, student-toteacher ratio, amount of bond, per pupil expenditure); election characteristics (e.g., time of year, past voting patterns, turnout, purpose of the issue); voter demographic characteristics (e.g., income, SES, education, home ownership, age, child status, gender); voter psychological characteristics (e.g., cynicism, educational attitudes, civic improvement orientation); information factors (e.g., source of information, use of citizen advisory committees, campaign techniques, media support); political characteristics (e.g., interest group activity, school-community relationships).
More specifically, Piele and Hall (1973a) found that while the overall size of a school district did not appear to affect the outcome of an election, increased overall voter turnout decreased the chances of passing a school bond. The authors state, "Although the use of these 'get out the vote' techniques represents an admirable faith in the 'democratic model,' they may well cause a new increase in negative voting" (1973a, p. 87). They also found that the time of year and purpose of the bond did not significantly factor into the outcome while voter income and voter educational level did. In the end, Piele and Hall describe the characteristics of voters most likely to vote in favor of school financial election as young parents of school age children that have a high level of education and income. Surprisingly, few studies since the 1970s have focused on modeling the factors associated with the likelihood of school bond elections passing or failing.

Recent studies on capital expenditure elections have varied, both in methodological approach and the subsequent findings. Holt, Wendt, and Smith (2006) found that the establishment of a diverse community task force and the dissemination of information regarding benefits to children and the community had a profound impact on the campaign. Two studies found selfinterest (currently having children in school) did not impact voting (Priest and Fox 2005) and election outcomes (Browkaw, Gale, and Merz 1990). However, these same studies found that trust in local school officials is important (Browkaw, Gale, and Merz 1990; Priest and Fox 2005). Finally, Berkman and Plutzer (2004) found that the impact of elderly voters mattered in educational expenditures in that concentrations of long-time elderly residents supported educational expenditures across 9000 districts while recent arrivals did not.

Current research has also used logistic or probit regression methods to estimate the parameters that are significant in modeling school district bond passage. Findings about specific significant parameters have been mixed, sometimes confirming and other times conflicting with each other. Sielke (1998) examined all proposed school bonds in Michigan between January and November, 1995, and found that a school district's current debt load and the general socio-economic status (SES) of the district were significant in predicting bond passage. Interestingly, while the SES finding replicated Piele and Hall (1973a) as a positive predictor, the amount of school debt was also a positive predictor. Specifically, school districts with high amounts of debt were more likely to pass additional bonds. The amount of the bond and the number of election attempts were non-significant (Sielke 1998). In contrast, Beckham and Maiden (2003) examined all bond proposals in Oklahoma from 1995 through 2000 and found that amount of the bond was significant: as the amount of the bond increased, passage rates decreased. They also identified the inclusion of technology in the wording of the bond proposal as a significant positive predictor of passage rates, and confirmed Sielke's (1998) findings that district enrollment generally was not a significant predictor (Beckham and Maiden 2003). Furthermore, while Sielke (1998) did not report an $\mathrm{R}^{2}$ statistic, Beckham and Maiden (2003) reported that their model accounted for approximately $10 \%$ of the variance in bond passage rates.

Following the findings from Sielke (1998), Zimmer and Jones (2005) used the district as the unit of analysis and modeled the successful issuance of bonds across 140 school districts in Michigan between 1991 and 1998. They found that previous 
district debt as well as if a district was either rural or town were significant in their model. More debt was positively related to districts issuing a bond, while rural and town locations were negatively related to bond issuance. The authors stated that their findings indicate that "voters in more leveraged school districts have greater tastes for debt... [and that] voters in more rural areas are less likely to vote favorably in bond referenda as compared to large cities and suburbs" (Zimmer and Jones, 2005, p.541). This is in comparison to the non-significant variables included in their model, including resident's income, property value per pupil, enrollment growth rate, percent population ages 5-19 and 65 or older, and the county unemployment rate.

More recently, Bowers, Metzger and Militello (2010) analyzed all proposed qualified school capital finance bonds in Michigan between 2000 and 2005 and reported four main findings. First, confirming Beckham and Maiden (2003), they found that as the amount of the bond increased the odds of the bond passing decreased. Second, in contrast to both Sielke (1998) and Beckham and Maiden (2003), district enrollment was a significant predictor of bond passage: as enrollment increased the odds of passing the bond also increased. Third, district locale was a significant parameter associated with bond passage. While midsized city and suburban school districts had relatively high overall chances of passing a bond, controlling for the other variables, rural school districts passed bonds at a much lower rate and small town school districts experienced the worst chances of all. Fourth, as the focus of the study, a district's chances of passing a bond were highest on the first attempt, with decreasing odds for subsequent "re-floats" of the same bond proposal. In the end, the model explained approximately $10 \%$ of the variance in bond passage rates in the Michigan case - comparable to Beckham and Maiden (2003) in Oklahoma.

Overall, these studies present a conflicting and fragmented model of the likelihood of passing a school bond. In order to build a coherent and updated research base, future studies should expand on the key issues tested in the earlier work. Relying on this previous literature, we identify seven major types of variables that have been tested in the past and need to be examined further for contemporary contexts in a single combined study to model the associated effects of each variable, while controlling for the others, using a recent and large dataset.

- SES and education levels of the community (Bradbury, Ladd, Perrault, Reschovsky, and Yinger 1984, Piele and Hall 1973a): Are the percentages of students in poverty in a district or the district's overall education levels associated with bond election outcome?

- Debt-load parameters (Sielke, 1998; Zimmer and Jones, 2005): Is the district's overall long-term debt a significant predictor of bond election outcomes?

- Technology (Beckham and Maiden 2003): Is the inclusion of wording to fund technology improvements in a bond proposal associated with the outcome of bond elections?

- Bond amount (Bowers, Metzger and Militello 2010; Beckham and Maiden 2003; Sielke 1998): Is the amount of money requested in the bond associated with the outcome of bond elections?

- Number of bond attempts and locale (Bowers, Metzger and Militello 2010, Sielke 1998): Do the number of "floats" or district type predict the outcome of bond elections?
- District enrollment (Bowers, Metzger and Militello 2010; Beckham and Maiden 2003; Piele and Hall 1973a; Sielke 1998): Is student enrollment associated with the outcome of bond elections?

- Voter turnout (Piele and Hall, 1973a): To what extent is voter turnout associated with the outcome of bond elections?

Furthermore, we suggest new variables that have received little attention since the 1970s:

- Day of year and proposal number on the ballot (Piele and Hall 1973a). Is the proposal's position on the ballot or when it is held during the year associated with the outcome of bond elections? Is it best for a capital request to appear as the first or only issue or to be listed among many funding requests on an election ballot?

\section{METHOD}

Our research was conducted by examining publicly available data on all qualified school bond loans (QSBL) in the state of Michigan for school capital improvements from 1998 through 2006, obtained from the Michigan Department of Treasury (Michigan Department of Treasury, n.d.). For details on Michigan's QSBL program, see Militello, Metzger and Bowers (2008) and Sielke et al. (2001). This resulted in 793 bond elections state-wide for the period, of which 394 passed $(49.7 \%)$ and 399 failed $(50.3 \%)$. However, only 789 bonds contained full data records (hence, for our study $n=789$ ). Variables obtained from the database for each bond included district name, election date, bond amount, votes yes, votes no, if the bond passed or failed, ballot number, and the complete text of each ballot as it was presented to voters.

To replicate and extend past research on the variables associated with passing or failing school bond elections, we then merged this bond database with the U.S. Department of Education/NCES Common Core of Data (CCD) (NCES, n.d.) for all districts that put a qualified bond up for election in Michigan, 1998-2006. District-level variables included district locale, total student enrollment each year, percent of students receiving free lunch, percent of local population with a high school diploma, percent of local voter turnout for the bond election, election day of the year, total amount of district long-term debt, and bond wording for technology. We constructed categories of school district locale using the locale codes from the National Center for Education Statistics (NCES), which are derived from the 2000 U.S. census designations. In our study, the mid-sized city-suburban category includes the urban core of mid-sized cities and the urban fringe of mid-sized and large cities. Our categories small town and rural are unchanged from the NCES locale codes. However, the Michigan Treasury database of bonds used for this research excluded large cities, such as Detroit, putting the large urban context beyond the scope of this study.

The remaining variables were constructed within the limitations of the data from the Michigan Treasury and the NCES CCD. Percent free lunch students is the percentage of enrolled students receiving subsidized free lunches. While "free and reduced price lunch students" would be preferable as a measure of economically disadvantaged students in a district, only data on 
Table 1: Michigan School District Bonds 1998-2006 by Locale, Number of Floats and Percent Pass.

\begin{tabular}{|c|c|c|c|c|c|c|c|c|}
\hline & \multicolumn{2}{|c|}{ First Float } & \multicolumn{2}{|c|}{ Second Float } & \multicolumn{2}{|c|}{ Third Float } & \multicolumn{2}{|c|}{ All Floats } \\
\hline & Total & \% Pass & Total & $\%$ Pass & Total & \% Pass & Total & \% Pass \\
\hline Mid-Sized City & 37 & 45.9 & 3 & 66.7 & 1 & 100.0 & 41 & 48.8 \\
\hline Suburban & 253 & $64.0^{\mathrm{a}}$ & 15 & 33.3 & 4 & 100.0 & 272 & $62.9^{\mathrm{e}}$ \\
\hline Small Town & 83 & 42.2 & 14 & $7.1^{\mathrm{b}}$ & 3 & 66.6 & 100 & $38.0^{f}$ \\
\hline Rural & 312 & 46.7 & 49 & $24.5^{c}$ & 15 & 33.3 & 376 & $43.1^{\mathrm{g}}$ \\
\hline All Districts & 685 & 52.4 & 81 & $24.7^{\mathrm{d}}$ & 23 & 52.2 & 789 & 49.6 \\
\hline
\end{tabular}

$\mathrm{a}-\chi^{2}(1, N=253)=18.82, p<0.005 ; \mathrm{b}-\chi^{2}(1, N=14)=10.28, p<0.005 ; \mathrm{c}-\chi^{2}(1, N=49)=12.76, p<0.005 ; \mathrm{d}-\chi^{2}(1, N=81)=20.75$, $p<0.005 ; \mathrm{e}-\chi^{2}(1, N=272)=18.01, p<0.005 ; \mathrm{f}-\chi^{2}(1, N=100)=5.76, \mathrm{p}<0.05 ; \mathrm{g}-\chi^{2}(1, N=376)=7.19, \mathrm{p}<0.01$

free lunch students were available from the CCD going back to 1998. Percent population with high school diploma was calculated using data from the 2000 U.S. census, dividing the total number of residents reporting having obtained only a high school diploma by the total number of residents age 18 or older and multiplying by 100 . This measure of educational attainment was used rather than "some college" due to the CCD listing only high school diploma, associate degrees and all college degrees. Percent voter turnout was calculated by dividing the total number of voters recorded for each bond election by the total number of residents age 18 or older in the 2000 U.S. census. While not a pure measure of voter turnout, this calculation is a reasonable proxy given the data available. Election day of the year is simply the number of the day of the year, from 1 to 365, reported for when the bond election was held (e.g., 42 corresponds to February 11). Proposal ballot number refers to the position of the bond on the election ballot reported to the state. However, the total number of issues on the ballot was not reported. Thus, position number indicates only relative position, not whether a bond is one among many issues on a ballot. District long-term debt is the total amount (in millions of dollars) reported at the start of the fiscal year for that school district and, thus, contains previous capital expenditures still being paid. To test previous hypotheses about the influence of the wording of bonds (Beckham and Maiden, 2003), the text of each ballot was coded as 0 or 1 for the absence or presence of wording pertaining to technology (including funding requests for computers, networking, and technology upgrades).

Furthermore, our analysis includes the number of reported election floats for the bond. A consistent strategy for school districts nationwide has been to "refloat" or "try again" to pass a bond that was previously rejected by voters (Bowers, Metzger and Militello 2010; Johnson 2008). Each bond was considered a separate case in the dataset. If a bond failed and was put back up for election within 12 months with substantively the same funding request and language, the bond was coded as a second float. Bonds were coded as third floats if the second float failed and the district put the bond back up again within another 12 months. As recommended for conditional datasets (Singer and Willet, 2003), a bond could not be considered for a second or third float unless it failed on the first or second float (a second or third float bond is conditional on the pass/fail status of the bond that preceded it). Of the 789 bonds in our sample, 685 were first floats; 326 of them failed. Of the first floats that failed, 81 were floated a second time; 61 failed. Of the second float bonds that failed, 23 were floated a third time; 11 failed. As recommended for conditional dependent data of this type, discrete-time hazard modeling using logistic regression was employed to estimate the probability of a district passing a school facilities bond (Bowers, Metzger and Militello, 2010). (For a more in-depth review of discrete-time hazard modeling, see Singer and Willet, 2003). In our analysis, bonds were coded as either having passed or failed an election, and a logistic regression was calculated with bond passage as the estimated outcome - where the float of each bond (a discrete time point) represents a pseudo-intercept conditional upon the previous float failing:

$\operatorname{Logit}(\mathrm{Y})=\alpha_{\text {First Float }} \mathrm{X}_{\text {First Float }}+\alpha_{\text {Second Float }} \mathrm{X}_{\text {Second Float }}+\alpha_{\text {Third }}$ Float $X_{\text {Third Float }}+\beta_{1} X_{1}+\beta_{2} X_{2}+\beta_{3} X_{3} \ldots$

To aid in model interpretation, estimated probabilities were generated for each bond by converting the logit estimates into probabilities $\left(1 /\left(1+\mathrm{e}^{-\operatorname{logit}}\right)\right)$ and fitted lines were plotted for the different district locale categories in the dataset against the data for each of the district-level and bond-level variables included in the final logistic regression model.

\section{RESULTS AND ANLYSIS}

In this section, we report the findings of our analysis of school bond data from across the state of Michigan from 1998-2006 $(n=789)$. Our purpose is to identify important differences in the rates of school bond elections passing or failing based on the variables explained above. In addition, we hope to articulate an expanded model of bond passage that contributes to the research base on capital bond election outcomes. Research over the past 20 years has identified multiple variables associated with passing or failing school facilities bonds. While many of these variables are statistically significant in the previous models, they have explained only about $10 \%$ of the variance in bond passage rates. In addition, few studies have examined all bonds for multiple years across an entire state-wide context. Our aim is to test an expanded model of school facilities bond passage that controls for the conditional nature of the data resulting from the practice of floating and refloating bonds. 
Table 2: Michigan School District Bond Means and Standard Deviations, 1998-2006

\begin{tabular}{lrrrrrr}
\hline & Passed & \multicolumn{1}{c}{ (SD) } & \multicolumn{1}{c}{ Failed } & \multicolumn{1}{c}{ (SD) } & Total & (SD) \\
\hline Bond Amount (in Millions \$) & 23.491 & $(29.303)$ & 22.7636 & $(38.951)$ & 23.175 & $(34.448)$ \\
Enrollment (in Thousands) & 3.327 & $(3.743)$ & 2.614 & $(2.883)$ & 2.973 & $(3.355)$ \\
Bond \$ per Enrolled Student & 7961.190 & $(6100.330)$ & 9392.535 & $(8670.589)$ & 8692.126 & $(7534.623)$ \\
Percent Free Lunch Students & 18.557 & $(12.492)$ & 22.516 & $(11.848)$ & 20.555 & $(12.315)$ \\
Percent Pop. with H.S. Degree & 30.715 & $(7.574)$ & 33.466 & $(5.993)$ & 32.109 & $(6.952)$ \\
Long Term Debt (in Millions \$) & 25.129 & $(40.465)$ & 10.543 & $(22.179)$ & 17.750 & $(33.328)$ \\
Percent Voter Turnout & 22.403 & $(11.305)$ & 26.757 & $(9.033)$ & 24.521 & $(10.514)$ \\
Election Day of the Year & 201.790 & $(82.834)$ & 181.660 & $(86.361)$ & 191.860 & $(85.158)$ \\
Ballot Number & 1.19 & $(0.542)$ & 1.47 & $(0.893)$ & 1.330 & $(0.752)$ \\
\hline
\end{tabular}

Floats

Bringing a previously rejected bond request before local voters a second or third time is far from an uncommon practice in the case of Michigan. If voters said no, why not try again? However, the actual frequencies over the period 1998-2006 are interesting, as shown in table 1 .

Overall, $52.4 \%$ of first-time bond requests passed. Only $24.7 \%$ of second floats passed. While third floats were, overall, a small sample, curiously they appeared to pass at nearly the same rate as first floats $(52.2 \%)$. When we bring district locale (mid-sized city/suburban, small town, and rural) into the picture, the results extend previous findings about Michigan school bonds (Bowers, Metzger and Militello, 2010). The initial bond request has relatively high chances of passing for all types of school districts, though this is most pronounced for suburban districts. Second floats have precipitously lower chances, though it does appear that chances may rise on a third attempt. However, does district locale tell us anything about the chances of passing a school bond in Michigan during this time period when we control for other variables that have been shown in previous literature to significantly predict bond election outcomes? Addressing this question requires a deeper look.

\section{Descriptive Statistics for Michigan School Bonds, 1998-2006}

Table 2 presents overall means and standard deviations for each variable, disaggregated by passed and failed bonds.

These descriptive statistics suggest important differences between districts with school bond elections that pass and that fail. On the surface, bond amount and district enrollment appear to show that larger bonds pass for schools with higher enrollment. However, when we control for district enrollment by instead looking at bond dollar per student enrolled in the district, the picture changes (row 3). Overall, asking for more money per student appears to correspond with failing bonds. Districts with failed bond elections asked for more money per student $(\$ 9,392.54)$ than districts with successful elections $(\$ 7,961.19)$.

Looking at the other variables allows us to construct a broader profile of school districts that pass or fail bond elections. Districts in which voters passed bond elections had a lower average percentage of students receiving federally subsidized free lunches ( $22.5 \%$ compared to $18.6 \%$ ). They had, on average, a slightly lower percentage of the local population that had only a high school degree (30.7\% compared to $33.5 \%$ ). They had, on average, a lower voter turnout $(22.4 \%$ compared to $26.8 \%)$. They held their bond elections later in the calendar year by an average of 20 days. They put the school bond request, on average, higher up the ballot, either as the only issue up for vote or as an issue voters reached before turning to subsequent issues on the same ballot. The further down the ballot, the more bond requests failed. However, perhaps the most intriguing finding is that districts in which voters passed bond elections had more than double the average amount of debt (\$25.1 million) than districts in which voters rejected school bond elections ( $\$ 10.5$ million). Districts with more outstanding debt from previous spending passed more school bond elections for future spending.

Though the variable is not included in table 2, we also analyzed whether having wording relating to "technology" in the text of the bond proposal was related to bond passage or failure. Our sample contained 793 bonds $(73.1 \%)$ with technology wording. Of the 394 bonds that passed, $296(75.1 \%)$ of them contained wording pertaining to technology. Of the 399 bonds that failed, 279 $(70.0 \%)$ of them contained wording pertaining to technology.

Our study looks at a wide range of variables with interesting, and in some cases surprising, results. Some appear to confirm findings from prior research discussed earlier, while others do not. In order to draw firmer conclusions using Michigan school bond elections 1998-2006, it is necessary to control for each variable in a logistic regression equation and model the chances of passing a bond. Which variables are significant and in what directions? This will aid in model building, testing/building theory, and helping administrators understand what variables were significant for the likelihood of passing a bond in Michigan from 1998-2006.

\section{Logistic Regression Models}

To estimate the likelihood of passing a bond to finance school facilities in Michigan from 1998-2006, we coded all bond elections as either passing or failing and calculated a logistic regression with bond passage as the estimated outcome. We report three different but cumulative models.

Model A replicates the previous study by Bowers, Metzger and Militello (2010), expanded to cover 1998-2006. The estimated parameters for Model A have the same direction, significance, and similar variance explained as the previous findings (summarized above). This model used two locale categories (rural and small town) with one reference group, mid-sized city/suburban. Mid-sized city, with the least number of bonds floated over this time period, by itself as a locale category, was not significant and did not significantly improve the fit of the 
model, so we combined it with suburban as the reference group in order to estimate a more parsimonious model (data not shown).

Table 3: Logistic regression model estimation of passing a Michigan school district facilities bond, 1998-2006.

\begin{tabular}{|c|c|c|c|}
\hline & Model A & Model B & Model C \\
\hline \multirow[t]{2}{*}{ First Float } & $0.490 * *$ & $1.233 * *$ & $3.212 * * *$ \\
\hline & $(0.171)$ & $(0.463)$ & $(0.680)$ \\
\hline \multirow[t]{2}{*}{ Second Float } & -0.456 & 0.373 & $2.292 * *$ \\
\hline & $(0.295)$ & $(0.521)$ & $(0.727)$ \\
\hline \multirow[t]{2}{*}{ Third Float } & 0.637 & $1.576^{*}$ & $3.450 * * *$ \\
\hline & $(0.436)$ & $(0.624)$ & $(0.827)$ \\
\hline \multirow{2}{*}{$\begin{array}{l}\text { Amount of Bond } \\
\text { (in Millions \$) }\end{array}$} & $-0.007 *$ & $-0.006 \sim$ & $-0.016 * * *$ \\
\hline & $(0.003)$ & $(0.004)$ & $(0.005)$ \\
\hline \multirow{2}{*}{$\begin{array}{l}\text { Enrollment } \\
\text { (in Thousands) }\end{array}$} & $0.058^{\sim}$ & -0.045 & -0.007 \\
\hline & $(0.033)$ & $(0.040)$ & $(0.044)$ \\
\hline \multirow[t]{2}{*}{ Small Town } & $-0.897 * * *$ & $-0.619 *$ & $-0.642 *$ \\
\hline & $(0.249)$ & $(0.260)$ & $(0.280)$ \\
\hline \multirow[t]{2}{*}{ Rural } & $-0.642 * * *$ & $-0.455^{*}$ & $-0.450 *$ \\
\hline & $(0.177)$ & $(0.193)$ & $(0.210)$ \\
\hline \multicolumn{2}{|l|}{ Percent Free } & $-0.014 *$ & $-0.017 *$ \\
\hline \multicolumn{2}{|l|}{ Lunch Students } & $(0.007)$ & $(0.007)$ \\
\hline \multicolumn{2}{|l|}{ Percent Pop with } & $-0.035^{*}$ & $-0.032 *$ \\
\hline \multicolumn{2}{|l|}{ H.S. Degree } & $(0.014)$ & $(0.016)$ \\
\hline \multicolumn{2}{|l|}{ (in Millions \$) } & & $\begin{array}{l}0.012 * * \\
(0.004)\end{array}$ \\
\hline \multicolumn{2}{|l|}{ Percent Voter } & & $-0.027 * *$ \\
\hline \multicolumn{2}{|l|}{ Turnout } & & (0.009) \\
\hline \multicolumn{2}{|l|}{ Election Day } & & $\begin{array}{l}0.003 * * * \\
(0.001)\end{array}$ \\
\hline \multicolumn{2}{|l|}{ Proposal Ballot } & & $-0.938 * * *$ \\
\hline \multicolumn{2}{|l|}{ Number } & & $(0.163)$ \\
\hline \multirow[t]{2}{*}{ Technology } & & & 0.011 \\
\hline & & & $(0.200)$ \\
\hline$N$ & 789 & 789 & 781 \\
\hline \multicolumn{4}{|l|}{ Goodness-of-fit } \\
\hline -2 Log Likelihood & 1045.373 & 1028.044 & 923.763 \\
\hline Cox and Snell $\mathrm{R}^{2}$ & 0.061 & 0.081 & 0.184 \\
\hline Nagelkerke $\mathrm{R}^{2}$ & 0.081 & 0.109 & 0.246 \\
\hline
\end{tabular}

Note: Parameter estimates are listed with standard errors in parentheses

Note: $\sim \mathrm{p} \leq 0.1 ; * \mathrm{p} \leq 0.05 ; * * \mathrm{p} \leq 0.01 ; * * * \mathrm{p} \leq 0.001$

Model B builds on the first model and adds two variables relating to community characteristics - a representation of families in poverty (percent free lunch) as well as a general proxy of educational attainment. Percent free lunch is significant and negative. Percent population with only a high school degree is significant and negative. District enrollment, which was marginally significant in Model A, becomes non-significant in Model B. Nonetheless, adding two community-level variables increases the estimated variance explained. Model B explains about $10 \%$ of the variance of the likelihood of passing a facilities bond in Michigan between 1998 and 2006 and is a significant improvement in fit over Model A, $\chi^{2}(2)=17.329, p<0.005$.
Model C, as our final model, builds on model B with bond-level variables that we drew from the prior literature. Controlling for the conditional nature of floating and refloating a bond as well as the other variables, we see many intriguing factors (see Table 3).

- Amount of the bond is negative and significant, implying that as the amount of the bond goes up the chances of passing go down.

- District enrollment is not significant (as in Model B), which is what would be expected based on the prior research.

- In terms of district locale (using mid-sized city/suburban as the reference group), the results for small towns and rural are negative and significant. On the whole, these districts have lower chances of passing a school bond.

- For percent free lunch students, the result is negative and significant. As our proxy for students in poverty goes up, the chances of passing go down.

- For percent population with only a high school degree, the result is also negative and significant. As our proxy for community level of basic educational attainment goes up, the chances of passing go down.

- District long-term debt is positive and significant factor: the higher the debt at the beginning of the fiscal year, the better the chances of passing the bond.

- Voter turnout is a negative and significant factor: the higher the turnout, the lower the chances of passing.

- As for the day of the year on which the election is held, the result is positive and significant: the later in the calendar year the bond election is held, the better the chances of passing.

- Regarding the proposal number of the ballot, the result is negative and significant: the further down the ballot for the voter, the worse the chances of passing.

- The inclusion of technology wording in the ballot text is not statistically significant.

Overall, Model $\mathrm{C}$ is a significant improvement in fit over Model $\mathrm{B}, \chi^{2}(2)=104.281, p<0.005$, and explains about $20 \%$ of the variance in the likelihood of passing a facilities bond in Michigan between 1998 and 2006. This doubles the amount of variance explained in all other recent prior research studies.

\section{Visualizing and Interpreting the Final Model of Bond Passage}

Since logistic regression coefficients and logit estimates are inherently difficult to interpret, plotting representative data is recommended (Singer and Willet, 2003). To aid in interpreting Model C, the logistic regression model was estimated for each bond in the dataset. Logits were then converted to estimated probabilities for passing a bond in Michigan from 1998-2006, from 0 to 1 . Fitted lines for each of the three locale categories were then plotted for the estimated probabilities of passing a bond in Michigan, 1998-2006, against each of the significant new variables in Model C. Figure 1 visualizes the different patterns of estimated likelihood of passing a bond for the different locales across each of the different variables. In all cases, when we report each variable, the model controls for all other variables included. 

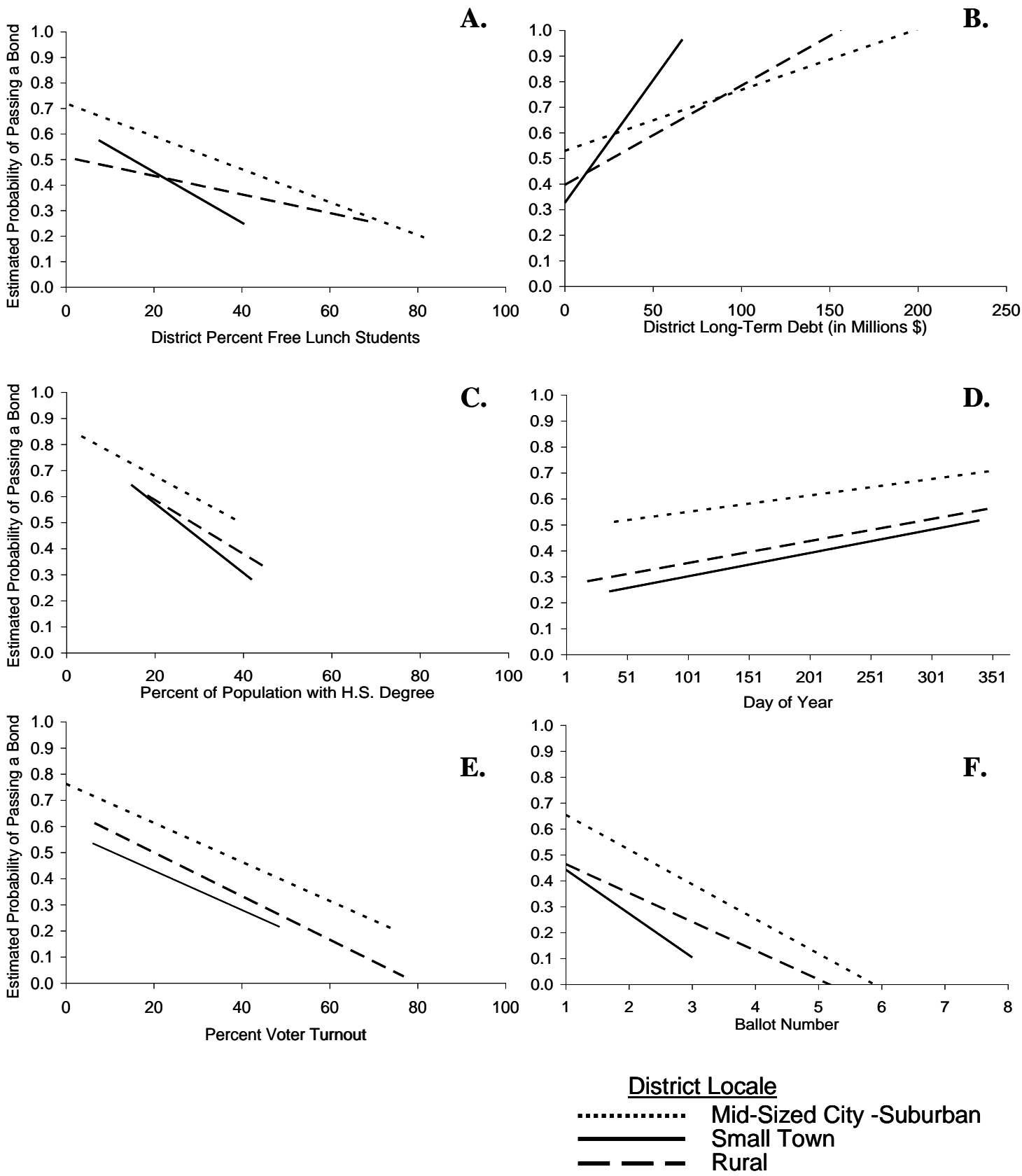

Figure 1: Logistic regression estimated probabilities of bond passage, plotted by significant variables in the logistic regression and disaggregated by locale. Probabilities for bond passage were estimated for each of the 789 Michigan school district facilities bonds, from 1998-2006. Fitted lines were then plotted for each of the three locale categories across the six different variables indicated in the panels, A-F. To help prevent over-extrapolation, fitted lines extend only for the range for each variable for each locale category. 
Overall, mid-sized cities/suburban districts had the best chances of passing a bond, followed by rural districts, with small town district bonds experiencing the worst chances (see Figure 1). However, when we look more closely at individual variables, the picture becomes more complex. The greater the percentage of students enrolled in a school district who receive federally subsidized free lunch, the less likely a district was to pass a bond (Figure 1A). This negative effect was strongest for small towns. If the district's percentage of free lunch students was above $20 \%$, the estimated chances of passing a bond were below $50 \%$. For all locales increased long-term debt for the district was positively related to the chances of passing a bond, and the effect was strongest for small towns (Figure 1B). The percentage of the local population 18 or older with only a high school degree negatively influenced the estimated chances of passing a bond for all district locales - though somewhat more so for small towns (Figure 1C). The calendar date on which the election is held appears to have been consistently positively related to election outcomes for all locales, with bonds floated later in the year passing more frequently (Figure 1D). The percentage of voter turnout was negatively associated with the estimated likelihood of passing a bond (Figure 1E). The number of the bond request on the election ballot was highly negatively and significantly associated with bond passage (Figure 1F). The further down on a ballot, the lower the chances of passing - and this relationship appears to be strongest for small towns.

\section{DISCUSSION}

\section{A Model of School Bond Passage for the 21st Century}

On the surface, there appears to be even odds of a school district getting a facilities bond request passed by local voters. Using the case of Michigan, of the 793 bond elections held between January, 1998, and December, 2006, 394 (49.7\%) passed and 399 $(50.3 \%)$ failed. However, attributing this to what amounts to a coin toss is hardly satisfying for school district leaders who need to find ways to fund the construction and renovation of school facilities. It is the obligation of educational policy research to produce both theory and association models for explaining the outcome of school bond elections. Given the pervasive inequity in school facilities and capital expenditures across the U.S. (Brunner and Rueben, 2001; Filardo, Vincent, Sung, and Stein, 2006; McPhail-Wilcox and King, 1986; Sielke, 2001), understanding what factors positively and negatively affect the passage of school bonds is urgent and timely.

With this in mind, we discuss our findings by way of relevant questions relating to school bond passage likelihood that should be of interest to educational researchers, policy makers, and school district leaders. These questions are addressed through our interpretation of our best analytical model (Model C), taking into consideration district locale and controlling for the other variables in the model.

\section{Do Community Characteristics Matter?}

In our interpretation, a community's poverty level, level of education, and capacity for taxing itself all matter. Put simply, controlling for other variables in the model, school districts that passed a facilities bond request in Michigan 1998-2006 on average had fewer poor students, a prior local track record of bond passage, and fewer residents with only high school diplomas.

Our study finds that as the percentage of students receiving free lunches in a district goes up, chances of that district getting a bond passed go down. This is what would be expected based on prior research (Sielke 1998). It also makes rational, if cold, sense: Controlling for everything else, school districts serving more economically disadvantaged students are less likely to pass bonds as often as other districts. As the percentage of the local population with only a high school degree goes up, chances of getting a bond passed go down. This appears to replicate prior research findings that voter education level is significant (Piele and Hall 1973a) - though older data were somewhat disjointed, with the direction of the effect differing based on geographical location. Our finding is curious, since it may seem plausible that more voters possessing a high school diploma would want wellfunded school facilities for the next generation. This is not what we see happening in the case of Michigan. Potentially, a higher proportion of voters with only a high school diploma could represent people who received fewer personal or economic benefits from their own educational experience and may feel less motivation to pay more for new schools. Additionally, the higher the district's existing debt at the start of the fiscal year, the better the chances of getting a bond passed. This is an expected finding based on prior research (Sielke 1998; Zimmer and Jones, 2005). We suggest that long-term debt is most likely a proxy for a district's "taxability": If a district has taxed itself in the past to improve facilities, it stands to reason that it would be more likely to tax itself again. When it comes to bond passage, perhaps past performance predicts future performance.

However, we must admit several limitations. The taxability proxy could work in the opposite causal direction - it is possible that some school district leaders are just particularly savvy at getting bonds passed. After all, even when we controlled for the requested bond amount, long-term debt was still a positive and significant factor. Additionally, our measure of poverty is narrow and stringent. Typically researchers use the number of students receiving free and reduced lunches as the proxy for poverty, but because reduced lunch numbers were not available to us we could only use the free lunch measure - and this may actually downplay the influence of poverty (which might have an even larger effect with a more inclusive measure). Furthermore, we use only a partial or preliminary proxy for level of community education, based on the Michigan data available to us. It is possible that including different measures of educational attainment could alter the result.

\section{Do School District Characteristics Matter?}

In our interpretation, a district's locale matters but not enrollment size. School districts trying to get a facilities bond request passed in Michigan 1998-2006 were less likely to pass their bonds if they were located in a rural locale and particularly in small town locales, regardless of small or large enrollments. That enrollment is non-significant is what should be expected based on most prior research (Piele and Hall, 1973a; Sielke, 1998; Zimmer and Jones, 2005 ) - though not in the previous study by Bowers, Metzger and Militello (2010). Our data here suggest that as we took into consideration more community-level parameters over a longer time span, enrollment ceased to be a significant factor. Perhaps the size of the population is outweighed by important characteristics of the population. 
As in the previous work, this study finds that locale is a significant factor. Everything else being equal, rural districts have less than middling chances of getting a school bond passed while small towns have the worst chances of all. In an earlier study of school facilities in Michigan, Militello, Metzger and Bowers (2008) observed that districts may ask for increasingly more in capital facilities bonds in order to "keep up with the Joneses". Differences in what school districts need and what they can get their voters to fund may be influenced by location. Our findings in this study suggest that conclusion may apply statewide, based on nearly ten years of evidence.

Do the Details of the Bond Matter?

In our interpretation, the amount requested for the bond and the number of times the bond is brought before voters both matter, but the inclusion of technology wording does not. School districts trying to get a facilities bond request passed in Michigan 19982006 were less likely to pass larger bonds with multiple floats. Additionally, in our model, wording pertaining to technology did not appear related to bond passage.

Our study finds that the more money a district asks for, the worse the chances of getting a bond passed. This is what would be expected based on the prior research (Beckham and Maiden, 2003; Bowers, Metzger and Militello 2010; Piele and Hall, 1973a; Sielke, 1998; Sielke 2001). It also makes rational sense: Everything else being equal, people rarely vote for higher taxes. Even when we controlled for current district long-term debt, bond amount was still a strongly negative and significant factor. Additionally, if a district fails to win a bond election the first time, chances fall on the second float. However, after two failed attempts, this study confirms previous work in suggesting that it may be worth a third try (Bowers, Metzger and Militello 2010). Furthermore, our study indicates that for Michigan by the late 1990s and 2000s, bond passage was not significantly related to the inclusion of wording pertaining to technology in the bond's ballot language, even though over $70 \%$ of all of the bonds examined contained technology wording. In contrast to this finding, Beckham and Maiden (2003) found that technology wording was a significant predictor of bond passage in Oklahoma. For the context of Michigan over this time-period, it may be that school districts were in need of technology upgrades to such an extent that inclusion of technology did not have an impact on bond passage. However, just as likely, this contrasting result could be due to geographical or regional political differences on the need for technology in schools. This finding points to interesting avenues for future research in the domain of funding for technology in school facilities funding requests.

\section{Do the Details of the Election Matter?}

In our interpretation, the time during a calendar year that a bond election is held, the position of the bond proposal on the ballot, and voter turnout all matter. School districts trying to get a facilities bond request passed in Michigan 1998-2006 were more likely to pass a bond when the election was held later in the year, the bond issue was at the top of the ballot, and the district experienced low voter turnout.

As in prior research (Johnson, 2008; Piele and Hall, 1973a), our study finds that higher voter turnout results in lower chances of getting a bond passed. Conventional wisdom is that small turnout consists mostly of yes-voting activists and that their influence is watered down as more voters come to the polls. Our study strongly suggests that this conventional wisdom may be right. In addition, school district leaders are rightly interested in what time of year is best to ask voters to fund facilities construction (Johnson, 2008). Our study finds that, controlling for the other variables in the model, for districts that floated bonds later in the year, those bonds passed more often. Possibly the early part of the year is a problematic time to ask voters for more money because tax bills are due, personal debt may be higher due to holiday spending, and the weather can be inclement (in Michigan heavy snows are often seen as late as early April, although they can also come as early as late October). What is particularly interesting is that, even controlling for voter turnout, holding the election later in the year is positive and significant. Potentially, around the beginning of a new school year, voters have school on their minds and may be more likely to say yes to new facilities construction. However, we must stress that caution must be taken when interpreting these findings. Our findings do not point to causal relationships, but rather we provide findings only from an association model of bond passage.

In a previous study Bowers, Metzger and Militello (2010) noted that school district leaders sometimes break up facilities funding requests into a number of smaller proposals on the same ballot instead of one omnibus proposal. The previous study asked but was unable to address whether or not doing so is a successful strategy. This study suggests that bond requests which are the first or only issue on the ballot have the best associated chances of passing. However, this variable is problematic because it is only a measure of bond position on the ballot and may not take into consideration the total number of issues on the ballot (including elected offices, other municipal facilities, referenda, etc.). Nonetheless, it may be reasonable that facilities bond requests that are the first or only issue have the best chances because there are fewer (or no) other issues to distract voter attention. After all, even controlling for voter turnout, being further down the ballot lowers the chances. It is possible that voters get "issue fatigue" when school bond proposals are among many others.

\section{CONCLUSIONS \& FUTURE DIRECTIONS}

We conclude that many factors influencing school bond passage identified in research literature from the late 20th century still hold for the case of Michigan, 1998-2006. More students in poverty, higher voter turnout, and larger bond amounts all are associated with lower chances of getting a bond request passed. On the other hand, some significant factors are new and interesting. Holding the election later in the calendar year and having the bond proposal as the first or only issue on the ballot are associated with higher chances of passing a school facilities bond. Our most important conclusion is that district locale matters. This is the fourth recent study concluding that type of locale - mid-sized city/suburban, small town, or rural - is a major influence on school facilities funding in Michigan (Bowers, Metzger and Militello 2010; Militello, Metzger and Bowers 2008, Zimmer and Jones, 2005).

It is necessary to stress that this study is not a prescription for how to win a school bond election. What held for Michigan over the past 10 years may not be generalizable to all school districts in Michigan or any other state. Our chief purpose is to help to build an updated model of bond passage likelihood in the hopes of constructing a broader theory. While considerable scholarly investigation was conducted in the 1960s-70s (Piele and Hall 
1973a, 1973b), school bond passage has received less attention by policy researchers in recent decades. What is needed is a theoretical model that takes into consideration the variables tested in the past and updates them for the 21 st century. We hope that our final model in this study lays groundwork for developing such a 21st-century knowledge base on school bond election outcomes.

Future research is necessary to construct a broader theory of bond passage. First, further investigation is needed to distinguish effects for mid-sized cities (like Lansing, Kalamazoo, or Flint in Michigan) from suburban districts as well as to account for large cities (Detroit, for example). Second, more research is needed on different strategies for bond proposals on a ballot. Our study only could examine whether or not the bond proposal was the first or only issue on the ballot. The influence of where the bond proposal is positioned among the known total number of issues on the ballot - and what those other issues are - remains to be studied. Third, this study does not address how or why each of the significant variables in the model act in districts attempting to pass bonds. Future qualitative research is needed to describe and understand the complex work and interrelationships of district and community actors during the bond proposal and election phases. Finally, replication is essential in building a general theory. In this study we hypothesize that certain factors seem to matter in getting school facilities bonds passed, but replication of findings and additional analysis is necessary before generalized claims can be made across time and different geographic contexts.

\section{RECOMMENDED CITATION FORMAT}

Bowers, A.J., Metzger, S.A., Militello, M. (2010) Knowing What Matters: An Expanded Study of School Bond Elections in Michigan, 1998-2006. Journal of Education Finance, 35(4), 374396. doi:10.1353/jef.0.0024

\section{REFERENCES}

Beckham, J., and Maiden, J. 2003. "The Effects of Technology Inclusion on School Bond Election Success in Oklahoma." Journal of Education Finance, 28(4): 557574.

Balsdon, E., Brunner, E. J., and Rueben, K. 2003. "Private Demands for Public Capital: Evidence From School Bond Referenda." Journal of Urban Economics, 54(3): 610-638.

Berkman, M., and Plutzer, E. 2004. "Gray Peril or Loyal Support? The Effects of The Elderly On Educational Expenditures." Social Science Quarterly, 85(5): 11781192.

Boschee, F. 2003. School Bond Success: A Strategy for Building America's Schools, 2nd edition. Lanham, MD: Scarecrow Education.

Boschee, F., and Holt, C. R. 1999. School Bond Success: A Strategy for Building America's Schools. Lanham, MD: Scarecrow Press.

Bowers, A.J., Metzger, S.A., Militello, M. 2010. "Knowing the Odds: Parameters that Predict Passing or Failing School District Bonds.” Educational Policy, 24(2): 398-420.

Bradbury, K. L., Ladd, H. F., Perrault, M., Reschovsky, A., and Yinger, J. 1984. "State Aid to Offset Fiscal Disparities Across Communities." National Tax Journal, 37(2): 151-170.
Brodsky, D. M., and Thompson, E. 1993. "Ethos, Public Choice, and Referendum Voting." Social Science Quarterly, 74(22): 286-299.

Browkaw, A. J., Gale, J. R., and Merz, T. E. 1990. "Explaining Voter Behavior Toward Local School Expenditures: The Impact of Public Attitudes." Economics of Education Review, 9(1): 67-72.

Brunner, E. J., and Rueben, K. 2001. "Financing New School Construction and Modernization: Evidence From California." National Tax Journal, 54(3): 527-539.

Conrad, C. 2002. "The Winning School Bond: A Citizen's Guide to a Successful School Bond Campaign." Lanham, MD: Scarecrow Education.

Crader, A., Holloway, K., and Stauffacher, A. 2002, March. Perceptions of Successful Strategies and Passage of School Bond Issues. Paper presented at the American Education Finance Association, Albuquerque, NM.

Davis, L., and Tyson, B. 2003. "Strategic Bonding." American School Board Journal, 190(7): 34-36.

Duncombe, W., and Wang, W. 2009. "School Facilities Funding and Capital-Outlay Distribution in the States." Journal of Education Finance, 34(3): 324-350.

Filardo, M. W., Vincent, J. M., Sung, P., and Stein, T. 2006. Growth and Disparity: A Decade of U.S. Public School Construction. Washington, DC: Building Educational Success Together (BEST).

Holt, C. R. 2009. School Bond Success: A Strategy for Building America's Schools. 3rd edition. Lanham, MD: Rowman and Littlefield Education.

Holt, C. R., Wendt, M., and Smith, R. 2006. "School Bond Success: An Exploratory Case Study." The Rural Educator, 27(2): 11-18.

Johnson, P. A. 2008. "Try, Try, Again: A Two-Step Strategy for Passing School Levies." Journal of School Public Relations, 29: 44-73.

Lifto, D., and Senden, J. B. 2006. "Watch Your Language! Words to Win by in Your Next School Finance Election." The School Administrator, 63(2): 42-45.

McPhail-Wilcox, B., and King, R. A. 1986. "Resource Allocation Studies: Implications for School Improvement and School Finance Research." Journal of Education Finance, 12(2): 191-222.

Michigan Department of Treasury. n.d.. Department of Treasury. Retrieved January, 5 2009, from Michigan Department of Treasury: http://www.michigan.gov/treasury

Militello, M., Metzger S., Bowers, A.J. 2008. "The High School "Space Race": Implications of a Market-Choice Policy Environment for a Michigan Metropolitan region. Education and Urban Society, 41(1): 26-54.

Mueller, D. C. 2003. Public Choice III. Cambridge, UK: Cambridge University Press.

Nagardeolekar, V., and Merritt, E. 2006. "The Subtle Stuff: What it Takes to Win Approval of a School Construction Bond." American School and University Magazine, 79(3): 296-299.

National Center for Educational Statistics. n.d.. Common Core of Data. Retrieved January 6, 2009, from http://nces.ed.gov.

Olsen, M. E. 1965. "Alienation and Political Opinions." Public Opinion Quarterly, 29(2): 200-212.

Piele, P. K., and Hall, J. S. 1973a. Budgets, Bonds, and Ballots: Voting Behavior in School Financial Elections. Lexington, Mass.: Lexington Books. 
Piele, P. K., and Hall, J. S. 1973b. Voting in School Financial Elections: Some Partial Theories. Eugene, OR: University of Oregon.

Priest, T., and Fox, L. 2005. "Minority Support for School Bonds in Charlotte-Mecklenburg: A Cautionary Note." Education and Urban Society, 37(2): 193-203.

Sanders, A. 1988. "Rationality, Self-Interest, and Public Attitudes on Public Spending." Social Science Quarterly, 69(2): 311-324.

Shabman, L., and Stephenson, K. 1994. "A Critique of The SelfInterested Voter-Model: The Case of a Local Single Issue Referendum.” Journal of Economic Issues, 28(4): $1173-1186$.

Sielke, C. C. 1998. "Michigan School Facilities, Equity Issues, and Voter Response to Bond Issues Following Finance Reform." Journal of Education Finance, 23(3): 309322.

Sielke, C. C. 2001. "Funding School Infrastructure Needs across the States." Journal of Education Finance, 27(2), 653662.

Sielke, C. C., Dayton, J., Holmes, T., and Jefferson, A. L. 2001. "Public School Finance Programs of the U.S. and Canada: 1998-99." Retrieved January 23, 2009, from http://nces.ed.gov/edfin/state_financing.asp.

Singer, J. D., and Willet, J. B. 2003. Applied Longitudinal Data Analysis: Modeling Change And Event Occurrence. New York: Oxford University Press.

Zimmer, R., and Jones, J.T. 2005. "Unintended Consequence of Centralized Public School Funding in Michigan Education." Southern Economic Journal. 71(3): 534544 